\title{
The role of sub-hippocampal versus hippocampal regions in bitemporal lobe epilepsies
}

Sandrine Aubert ${ }^{1,2}$, Francesca Bonini ${ }^{1,7}$, Jonathan Curot $^{3}$, Luc Valton ${ }^{3}$, William Szurhaj ${ }^{4}$, Philippe Derambure ${ }^{4}$, Sylvain Rheims ${ }^{5}$, Philippe Ryvlin ${ }^{5}$, Fabrice Wendling ${ }^{6}$, Aileen McGonigal $^{1,7}$, Agnes Trébuchon ${ }^{1,7}$, Fabrice Bartolomei ${ }^{1,2,7}$

1) CHU Timone, Service de Neurophysiologie Clinique, Marseille, France

2) Aix Marseille Univ, Inserm, INS, Institut de Neurosciences des Systèmes, Marseille, France

3) Service des Neurologie et d'Explorations Neurophysiologiques Fonctionnelles Neurologiques, Hôpital Pierre Paul Riquet, Rangueil, et CERCO, UMR 5549, CNRS, Université de Toulouse, Toulouse, France

4) Service de Neurophysiologie Clinique, Hôpital Salengro, Lille, France

5) Service de Neurologie Fonctionnelle et Epileptologie, Hospices Civils de Lyon, France

6) Université de Rennes 1, LTSI, INSERM, U642, Rennes, France.

7) Federation Hospitalo Universitaire (FHU) «Epinext » A*MIDEX, Aix Marseille Université

\section{Corresponding Author:}

Pr Fabrice Bartolomei, MD, PhD

Service de Neurophysiologie Clinique

CHU Timone-264 Rue st Pierre

13005-Marseille, France

Tel :+33491385833 Fax :+33491385826

E-mail : fabrice.bartolomei@ap-hm.fr 


\begin{abstract}
Objective: We aimed at better delineating the functional anatomical organization of bitemporal lobe epilepsy.
\end{abstract}

Methods: We studied the epileptogenic zone (EZ) by quantifying the epileptogenicity of brain structures explored by depth electrodes in patients investigated by stereoelectroencephalography (SEEG). We compared 15 patients with bilateral mesial temporal lobe epilepsy (BTLE) and 15 patients with unilateral mesial temporal lobe epilepsy (UTLE). This quantification was performed using the 'Epileptogenicity Index' (EI)

Results: Age at epilepsy onset, and epilepsy duration, were not statistically different in both groups. UTLE patients more frequently displayed maximal epileptogenicity in hippocampal structures, whereas BTLE patients had maximal values in subhippocampal areas (entorhinal cortex, temporal pole, parahippocampal cortex).

Conclusions: Our results suggest different organization of the EZ in the two groups

Significance: BTLE was associated with more involvement of subhippocampal regions, a result in agreement with known anatomical connections between the two temporal lobes.

Keywords: Entorhinal cortex, Bilateral Temporal epilepsy, SEEG, Surgery, Epileptogenicity Index. 


\section{Highlights}

- Epileptogenicity distribution of bilateral versus unilateral TLE was evaluated with SEEG.

- Unilateral TLE patients displayed epileptogenicity mostly in hippocampal structures.

- Bilateral TLE patients displayed epileptogenicity mostly in subhippocampal regions. 


\section{Introduction}

Bitemporal lobe epilepsies (BTLE) are characterized by seizures arising independently or starting simultaneously from the two temporal lobes (So et al. , 1989) and are a major source of concern in the context of epilepsy surgery. The suspicion of BTLE is a usual indication for depth electrode exploration in temporal lobe epilepsy (TLE) (Diehl et al. , 2000). Previous studies have shown that BTLE may account for 20\% of TLE patients explored by depth EEG (Hirsch et al. , 1991). Anterior temporal lobectomy is often proposed when a majority of seizures arise from one side (So et al. , 1989, Hirsch et al. , 1991) but cognitive risks are significant and outcome is generally less favorable. Factors contributing to bilaterality in TLEs are unclear. No specific etiological factors have been significantly correlated to BTLE (So et al. , 1989, Hirsch et al., 1991, Lim et al., 1991, Sirven et al. , 1997). From experimental models of mirror foci, it has been suggested that bilaterality could be due to a secondary epileptogenesis process(Morrell, 1991). However, somewhat against this hypothesis is the observation that bilaterality has not been clearly correlated with epilepsy duration or age at onset (Steinhoff et al. , 1995).

In the present work we aimed at studying the functional anatomy of the epileptogenic zone (EZ) in patients undergoing bilateral SEEG exploration for mesial TLE. We particularly wished to establish whether the anatomo-functional structure of the EZ is different in patients presenting unilateral versus bilateral TLE. In particular, it has been suggested that some structural factors (notably hippocampal sclerosis) may influence bilaterality (Duckrow et al. , 1992). In addition, interhemispheric connectivity linking subhippocampal regions (rhinal cortices including entorhinal cortex, perirhinal cortex and parahippocampal cortex) appear to be stronger than connections between the two hippocampi in humans (Gloor, 1997, Adam, 
2006). It is not known however if the pathophysiology of BTLE affects the subhippocampal regions more than the hippocampus.

To gain insight into this question, we analyzed data obtained in patients explored by SEEG and presenting either BTLE or unilateral TLE (UTLE). The epileptogenicity of mesiotemporal brain structures was estimated using the Epileptogenicity Index (EI), a method previously described to quantify the epileptogenic zone networks (Bartolomei et al. , 2008, Bartolomei et al. , 2010)

\section{Methods}

\section{Patient selection and SEEG recordings}

Patients with either BTLE or UTLE explored by SEEG were selected for this study. BTLE were defined as patients whose habitual seizures were characterised by independent mesial temporal onset from each side (more than $20 \%$ of seizures) or bilateral onset (discharge affecting both mesial temporal structures with latency of less than one second). UTLE were defined as patients whose seizures started from a unilateral mesial temporal region during the SEEG video recordings. We retained for this study only patients having undergone bilateral exploration with at least one contralateral mesiotemporal electrode. Since BTLE is relatively less prevalent than UTLE, we collected data from 15 consecutive patients with BTLE recorded in four French epilepsy centers (Marseille, Lyon, Lille, Toulouse). These patients were compared with 15 UTLE patients investigated in the presurgical epilepsy unit at the Timone hospital in Marseille during the same period. These patients had strictly unilateral onset of temporal lobe seizures during SEEG recordings. After surgical procedures most of 
the patients with UTLE were seizures free (table 1). In case of seizure relapse after surgery, residual seizures were recorded and were located in the same side, thus excluding an unsuspected BTLE revealed in these cases.

All patients had SEEG implantation including exploration of the hippocampal region (anterior hippocampus, aHip and/or posterior hippocampus, pHip), sub-hippocampal regions (entorhinal cortex, EC), posterior part of the para-hippocampal gyrus (pPHG), amygdala (Amy) and temporal pole (TP).

All patients had SEEG after a comprehensive evaluation including detailed history and neurological examination, routine brain MRI, video-EEG recordings. Most of them also had positron emission tomography (FDG-PET), ictal and/or interictal single-photon emission computed tomography (SPECT) imaging, and neuropsychological testing.

SEEG exploration was carried out during long-term video-EEG monitoring, as part of our patients' normal clinical care. Recordings were performed using intracerebral multiple contact electrodes (5 to 15 contacts, length: $2 \mathrm{~mm}$, diameter: $0.8 \mathrm{~mm}, 1.5 \mathrm{~mm}$ apart) placed intracranially according to Talairach's stereotactic method (Bancaud et al. , 1965, Guenot et al. , 2001). The targeting of electrodes was established in each patient based upon available noninvasive information and hypotheses about the localization of the epileptogenic zone. VideoEEG recording was prolonged as long as necessary for the recording of several habitual seizures.

SEEG signals were sampled at $256 \mathrm{~Hz}$ or 512 and recorded on a hard disk using no digital filter. Habitual spontaneous seizures or seizures induced by low frequency (bipolar stimulation, $1 \mathrm{~Hz}, 2 \mathrm{~ms}$ pulse width, intensity range: $0.3-1.5 \mathrm{~mA}$ ) electrical stimulation were analyzed. All available seizures (mean 5.2, range 2-11) were analysed in the BTLE group (as 
seizure patterns greatly varied from one seizure to another), and a minimum of 2 seizures (mean: 3.13, range 2-7) analysed in the UTLE group.

\section{Signal analysis: definition and computation of the Epileptogenicity Index (EI)}

Our study was based on the determination of the "Epileptogenicity Index" (EI). This quantification has been proposed in order to characterise the propensity of a given brain structure to generate a 'rapid discharge' (the high frequency oscillations observed during the transition between ictal and interictal activity) and takes into account the delay of appearance of this discharge with respect to seizure onset (Bartolomei et al. , 2008, Bartolomei et al. , 2010, Bartolomei et al. , 2011) (for details see Supplementary Material). The purpose of this index is to provide quantified information about the behaviour of brain structures recorded from signals they generate during the seizure process. This index summarises two pieces of information into a single quantity: 1) whether or not the recorded brain structure is involved in the generation of a high frequency discharge (beta and gamma range) and 2) when involved, whether or not this rapid discharge is delayed with respect to rapid discharges generated by other structures. A normalised value is used ranging from 0 to 1 . If there is no involvement of the brain structure, the EI $=0$ whereas if the brain structure generates a rapid discharge and

the time to seizure onset is minimal, the $\mathrm{EI}=1$. An EI between 0 and 1 corresponds to secondary involvement of the brain structure concerned (for detailed methodology see (Bartolomei et al. , 2008))

In practice, we use a semi-automatic approach: using a handy graphical user interface, the user can easily inspect and validate automatically detected change points indicating the 
accurate onset of rapid discharges. From this validation performed on a "structure-bystructure" basis, the EI is then computed.

We determined the EI values from signals recorded in distinct structures ( 7 or 8 in each patient) including all mesial temporal regions available in our patients. A structure was considered as being highly epileptogenic when its EI value was $\geq 0.4$, according to previous reports (Bartolomei et al. , 2010). Generally, the implantation strategy favored one side with a complete set of explored regions. We therefore quantified the EZ from the predominantly explored side.

The SEEG signals from the following regions were analyzed in each selected patient: anterior hippocampus (aHip), posterior hippocampus (pHip); entorhinal cortex (EC); internal part of the temporal pole (iTP); parahippocampal cortex (pPHG) and amygdala (A).

\section{Statistical analysis}

Statistical analysis was performed to assess potential links between the bilateral or unilateral nature of the related epilepsy and EZ location / organization, as well as several clinical and imaging data. Qualitative clinical data between the two groups (UTLE and BTLE) were compared using chi square or Fisher exact tests. EI values computed from mesiotemporal regions were compared between the two groups (BTLE, UTLE). All statistical tests were performed on mean EI values calculated from all available seizures for each patient. A total of 116 seizures were analyzed ( 3.8 seizures / patient).

EI values were averaged over different subgroups of structures (hippocampal structures including aHip and pHip; subhippocampal structures including EC, pPHG and iTP; amygdala). They were then compared using non-parametric tests (Mann-Whitney) because 
values did not follow normal distribution. A p-value smaller than or equal to 0.05 was considered to be statistically significant. Statistical tests were performed with the software SPSS for Windows, version 13.1.

\section{Results}

\section{Clinical data}

The main characteristics of the two studied populations are summarized in table 1. Comparing BTLE and UTLE, we did not find significant differences in sex ratio, even if we found a slight female predominance in BTLE ( $\mathrm{p}=0.14)$. Age at epilepsy onset, and epilepsy duration, were not statistically different in the two groups (15.8 years (+/- 8.8) vs 15.6 years $(+/-11.9)$, $\mathrm{p}=0.61)$ and 23.2 years $(+/-10.8)$ vs 20.9 years $(+/-14.8)(\mathrm{p}=0.42)$. Past history of febrile seizures was less frequently reported in the BTLE group than in the UTLE group, without reaching a significant level (2/15 vs $5 / 15, \mathrm{p}=0.19)$. Three patients in the BTLE group and one in the UTLE group had a past history of post-ictal psychosis.

BTLE patients more frequently displayed bilateral interictal spikes than UTLE patients (73\% vs $46 \%, p=0,036)$. Bilateral temporal hypometabolism on FDG PET was more frequently present in the BTLE group ( $33 \%$ vs $7 \%, \mathrm{p}<0,0001)$. False-lateralizations were obseryed, when comparing FDG PET results with SEEG findings (predominant side for BTLE patients, definite side for UTLE patients): $33 \%$ in the BTLE group, vs $0 \%$ in the UTLE group.

Global IQ was slightly lower in the BTLE group (75.8 +/- 20.6 (range 46-116); UTLE: $81.4+/-10.3$ (72-100); $\mathrm{p}=0.047)$, but visuo-verbal discrepancy was represented equally in both groups (BTLE 3/15, 20\%; UTLE patients $(6 / 15,40 \%), p=0.20)$. No significant 
differences were found in the etiology of epilepsy $(\mathrm{p}=0.52)$ but HS was slightly more frequent in the UTLE group (7 patients vs 4 in the BTLE group).

Only one patient in the BTLE group has been operated (anterior temporal lobectomy (ATL) leading to a class III outcome). In the UTLE group, 13 patients benefited from ATL (among whom, $10(76 \%)$ have Engel Class I outcome,) and one had Gamma knife radiosurgery targeting the mesial temporal lobe (Class I Engel at the last follow up, 3y).

\section{SEEG data: Epileptogenicity index analysis}

Table 2 summarizes the SEEG findings in both groups. Figures 1 and 2 show examples of BTL seizures. The epileptogenicity profiles as determined by EI computation of the signal from different mesio-temporal sub-regions were found to be different in the two groups. We indeed found a trend in the BTLE group for higher EI values in the posterior part of the parahippocampal gyrus ( $\mathrm{pPHG})(\mathrm{p}=0.05)$ and a significant difference for the anterior hippocampus (aHip), with a higher epileptogenicity of this structure in UTLE patients $(\mathrm{p}=0.005)$ (Fig 3). Results therefore suggest that BTLE patients tended to have a subhippocampal epileptogenic zone, whereas the EZ in UTLE patients predominantly involved hippocampus. This tendency was confirmed when we studied averaged values obtained from amygdala, hippocampal region (regrouping aHip and pHip), and subhippocampal regions (including EC, pPHG and iTP values). The two groups were significantly different for hippocampal values, these being higher in the UTLE patients than in BTLE patients $(\mathrm{p}=0.01)$. 
Among BTLE patients, 11 had a bilateral TL seizure onset (bilateral subtype) with an over-representation of subhippocampal EZ $(n=7)$, whereas only half of the remaining 4 with right and left TL seizures (independent subtype) had a subhippocampal EZ.

The mean total number of epileptogenic structures was calculated by considering EI values above a heuristic threshold (0.4) and including the explored mesiotemporal region. The number of regions disclosing EI>0.4 was similar in both groups: $2.13+/-0.64$ in BTLE patients vs $2.2+/-1.15$ than in the UTLE group ( $>00.05$ ).

\section{Discussion}

This study aimed at determining the functional anatomy of the EZ in bilateral temporal lobe epilepsies in comparison with unilateral temporal lobe epilepsies. Results are in favor of more marked subhippocampal epileptogenicity in patients with BTLE, while epileptogenicity predominated in the hippocampus in patients with UTLE. These results were obtained by using a quantification of the seizure onset zone by the mean of the epileptogenicity index, a semi-automated method aimed at quantifying the seizure onset zone from depth EEG recordings (Bartolomei et al. , 2008, Bartolomei et al. , 2010, Bartolomei et al. , 2011).

The included BTLE patients had characteristics in agreement with previous studies. In particular no specific etiological factors were found to differentiate the two populations, although HS was slightly more frequent in the UTLE patients (Hirsch et al. , 1991, Lim et al. , 1991, Janszky et al. , 2003). Bilaterality was also not linked to the epilepsy duration, a finding previously reported (Napolitano et al. , 2008, Boling et al. , 2009). 
Our findings rather suggest that bilaterality is associated with particular anatomical and functional pathways. We indeed found that, within mesial networks, sub-hippocampal regions may be prominently epileptogenic in BTLE. These regions include the entorhinal and perirhinal cortices anteriorly and the parahippocampal cortex posteriorly (Amaral et al. , 1990, Insausti et al. , 1995). Clinical and experimental evidence have demonstrated that that the EC is a key structure participating in epileptogenic networks in MTLE (Spencer ef al. , 1994, Bartolomei et al. , 2004, Bartolomei et al. , 2005). Using a nonlinear measure of SEEG signal interdependencies the EC was found to be the leader structure in almost half of the patients' seizures and a correlation was found between EC atrophy and its leadership during seizures (Bartolomei et al. , 2004, Bartolomei et al. , 2005). Some experimental studies also suggested that the EC may have a lower seizure threshold than the hippocampus (Wilson et al. , 1988, Bragdon et al. , 1992, Heinemann et al. , 1993). The fact that subhippocampal regions including the EC are more epileptogenic in bitemporal epilepsies is however a novel finding.

The specific role of these subhippocampal regions in bitemporal epilepsies could be linked to their dense connections in human with the contralateral temporal regions, in contrast with the hippocampal formation (Adam, 2006). Three commissures connect the temporal lobes: the anterior commissure (AC), the ventral hippocampal commissure (VHC) and the dorsal hippocampal commissure (DHC). Compared to lower mammals, inter-hippocampal connections are less developed in human. Indeed, the VHC (connecting the hippocampi in lower mammals like rats) is almost absent in primates. The DHC connects the entorhinal cortex to presubiculum (Amaral et al. , 1984) and the homologous parahippocampal gyri (Demeter et al. , 1985). This phylogenic trend (quasi-disappearance of the VHC) has been confirmed in humans by an autopsy study (Gloor et al. , 1993). Inter-amygdalar connections have also decreased in human brains (Demeter et al. , 1990). In humans, the anterior commissure (AC) appears as a major source of bitemporal connexions from the 
subhippocampal regions. The AC forms an important fiber bundle ensuring the bidirectional connexion of the anterior part of the temporal lobes, including temporal pole and parahippocampal regions. The AC could be further developed in humans compared to those of non-human primates (Di Virgilio et al. , 1999).

Adam et al described a case with a fast ( 100 milliseconds) contralateral propagation of after-discharges induced by trains of $50 \mathrm{~Hz}$ stimulations, only when they were applied in the perirhinal cortex, and hypothesized that this "direct transcommissural transfer" was achieved through the anterior commissure (Adam et al. , 2004). Two recent studies have investigated connections between human temporal (and frontal) cortices by intracranial electroencephalographic responses to 1-ms single pulses electrical stimulations. Contralateral temporal connections were rare but more frequent between entorhinal cortices or fusiform cortices (Lacruz et al. , 2007, Jimenez-Jimenez et al., 2015). More recently, the DHC (but not the VHC) was found in the brains of healthy subject using MRI tractography (ColnatCoulbois et al. , 2010). It has been already shown that short $(<5 \mathrm{sec})$ or very short $(<0.5 \mathrm{sec})$ interhemispheric propagation times are negative prognostic factors for post-surgical outcome in TLE (Lieb et al. , 1986).

Our findings are in keeping with these anatomical findings, as our BTLE patients displayed a subhippocampal EZ (located in EC and/or pPHG) and we can postulate that this bilateral condition is sustained by its specific anatomic connections.

The treatment of BTLE is particularly problematic and disappointing. Surgery can be considered in cases with a predominant side, but the often disappointing results of this approach indicate that other therapeutic options should be developed. Among these, chronic stimulations of the hippocampus have been proposed, with variable long-term results (McLachlan et al. , 2010, Vonck et al. , 2013). However, our findings suggest that targeting the entorhinal/parahippocampal cortex could be an interesting alternative in this perspective. 


\section{Conflict of interest}

None of the authors has any conflict of interest to disclose.

\section{Acknowledgements}

We thank Prof Jean Regis and Dr Romain Carron (Functional Neurosurgery department, Marseille), Prof Jean-Christophe Sol (Neurosurgery department, Toulouse), Dr Nicolas Reyns (Neurosurgery department, Lille), and Prof Marc Guenot (Neurosurgery department, Lyon) for SEEG and surgical procedures. We thank Virginie Laguitton for neuropsychological examination. 


\section{References}

Adam C. How do the temporal lobes communicate in medial temporal lobe seizures? [In French]. Rev Neurol (Paris). 2006;162:813-8.

Adam C, Hasboun D, Clemenceau S, Dupont S, Baulac M, Hazemann P. Fast contralateral propagation of after-discharges induced by stimulation of medial temporal lobe. J Clin Neurophysiol. 2004;21:399-403.

Amaral D, Insausti R. Hippocampal formation. In: Paxinos G, editor. Tha Human Nervous System. San Diego: Academic Press; 1990. p. 711-57.

Amaral DG, Insausti R, Cowan WM. The commissural connections of the monkey hippocampal formation. J Comp Neurol. 1984;224:307-36.

Bancaud J, Talairach J, Bonis A, Schaub C, Szikla G, Morel P, et al. La stéréoélectroencéphalographie dans l'épilepsie: informations neurophysiopathologiques apportées par l'investigation fonctionnelle stereotaxique. Paris: Masson; 1965.

Bartolomei F, Chauvel P, Wendling F. Epileptogenicity of brain structures in human temporal lobe epilepsy: a quantified study from intracerebral EEG. Brain. 2008;131:1818-30.

Bartolomei F, Cosandier-Rimele D, McGonigal A, Aubert S, Regis J, Gavaret M, et al. From mesial temporal lobe to temporoperisylvian seizures: a quantified study of temporal lobe seizure networks. Epilepsia. 2010;51:2147-58.

Bartolomei F, Gavaret M, Hewett R, Valton L, Aubert S, Regis J, et al. Neural networks underlying parietal lobe seizures: a quantified study from intracerebral recordings. Epilepsy Res. 2011;93:164-76.

Bartolomei F, Khalil M, Wendling F, Sontheimer A, Regis J, Ranjeva JP, et al. Entorhinal cortex involvement in human mesial temporal lobe epilepsy: an electrophysiologic and volumetric study. Epilepsia. 2005;46:677-87.

Bartolomei F, Wendling F, Regis J, Gavaret M, Guye M, Chauvel P. Pre-ictal synchronicity in limbic networks of mesial temporal lobe epilepsy. Epilepsy Res. 2004;61:89-104.

Boling W, Aghakhani Y, Andermann F, Sziklas V, Olivier A. Surgical treatment of independent bitemporal lobe epilepsy defined by invasive recordings. J Neurol Neurosurg Psychiatry. 2009;80:533-8. 
Bragdon AC, Kojima H, Wilson WA. Suppression of interictal bursting in hippocampus unleashes seizures in entorhinal cortex: a proepileptic effect of lowering $[\mathrm{K}+]$ o and raising [Ca2+]o. Brain Res. 1992;590:128-35.

Colnat-Coulbois S, Mok K, Klein D, Penicaud S, Tanriverdi T, Olivier A. Tractography of the amygdala and hippocampus: anatomical study and application to selective amygdalohippocampectomy. J Neurosurg. 2010;113:1135-43.

Demeter S, Rosene DL, Van Hoesen GW. Interhemispheric pathways of the hippocampal formation, presubiculum, and entorhinal and posterior parahippocampal cortices in the rhesus monkey: the structure and organization of the hippocampal commissures. J Comp Neurol. 1985;233:30-47.

Demeter S, Rosene DL, Van Hoesen GW. Fields of origin and pathways of the interhemispheric commissures in the temporal lobe of macaques. J Comp Neurol. 1990;302:29-53.

Di Virgilio G, Clarke S, Pizzolato G, Schaffner T. Cortical regions contributing to the anterior commissure in man. Exp Brain Res. 1999;124:1-7.

Diehl B, Luders HO. Temporal lobe epilepsy: when are invasive recordings needed? Epilepsia. 2000;41 Suppl 3:S61-74.

Duckrow R, Spencer S. Regional coherence and the transfer of ictal activity during seizure onset in the medial temporal lobe. Clin Neurophysiol. 1992; 82:415-22.

Gloor P. The Temporal lobe and Limbic system. New York-Oxford: Oxford University Press; 1997.

Gloor P, Salanova V, Olivier A, Quesney LF. The human dorsal hippocampal commissure. An anatomically identifiable and functional pathway. Brain. 1993;116:1249-73.

Guenot M, Isnard J, Ryvlin P, Fischer C, Ostrowsky K, Mauguiere F, et al.

Neurophysiological monitoring for epilepsy surgery: the Talairach SEEG method. StereoElectroEncephaloGraphy. Indications, results, complications and therapeutic applications in a series of 100 consecutive cases. Stereotact Funct Neurosurg. 2001;77:29-32. Heinemann U, Zhang CL, Eder C. Entorhinal cortex-hippocampal interactions in normal and epileptic temporal lobe. Hippocampus. 1993;3 Spec No:89-97. 
Hirsch LJ, Spencer SS, Williamson PD, Spencer DD, Mattson RH. Comparison of bitemporal and unitemporal epilepsy defined by depth electroencephalography. Ann Neurol. 1991;30:340-6.

Insausti R, Tunon T, Sobreviela T, Insausti A, Gonzalo L. The human entorhinal cortex: a cytoarchitectonic analysis. J Comp Neurol. 1995;355.:171-98.

Janszky J, Rasonyi G, Clemens Z, Schulz R, Hoppe M, Barsi P, et al. Clinical differences in patients with unilateral hippocampal sclerosis and unitemporal or bitemporal epileptiform discharges. Seizure. 2003;12:550-4.

Jimenez-Jimenez D, Abete-Rivas M, Martin-Lopez D, Lacruz ME, Selway RP, Valentin A, et al. Incidence of functional bi-temporal connections in the human brain in vivo and their relevance to epilepsy surgery. Cortex. 2015;65:208-18.

Lacruz ME, Garcia Seoane JJ, Valentin A, Selway R, Alarcon G. Frontal and temporal functional connections of the living human brain. Eur J Neurosci. 2007;26:1357-70.

Lieb JP, Engel J, Jr., Babb TL. Interhemispheric propagation time of human hippocampal seizures. I. Relationship to surgical outcome. Epilepsia. 1986;27:286-93.

Lim SH, So NK, Luders H, Morris HH, Turnbull J. Etiologic factors for unitemporal vs bitemporal epileptiform discharges. Arch Neurol. 1991;48:1225-8.

McLachlan RS, Pigott S, Tellez-Zenteno JF, Wiebe S, Parrent A. Bilateral hippocampal stimulation for intractable temporal lobe epilepsy: impact on seizures and memory. Epilepsia. 2010;51:304-7.

Morrell F. The role of secondary epileptogenesis in human epilepsy. Arch Neurol. 1991;48:1221-4.

Napolitano CE, Orriols M. Two types of remote propagation in mesial temporal epilepsy: analysis with scalp ictal EEG. J Clin Neurophysiol. 2008;25:69-76.

Sirven JI, Malamut BL, Liporace JD, O'Connor MJ, Sperling MR. Outcome after temporal lobectomy in bilateral temporal lobe epilepsy. Ann Neurol. 1997;42:873-8.

So N, Olivier A, Andermann F, Gloor P, Quesney LF. Results of surgical treatment in patients with bitemporal epileptiform abnormalities. Ann Neurol. 1989;25:432-9. 
Spencer S, Spencer D. Entorhinal-hippocampal interactions in medial temporal lobe epilepsy. Epilepsia. 1994;35:721-7.

Steinhoff BJ, So NK, Lim S, Luders HO. Ictal scalp EEG in temporal lobe epilepsy with unitemporal versus bitemporal interictal epileptiform discharges. Neurology. 1995;45:889-96.

Vonck K, Sprengers M, Carrette E, Dauwe I, Miatton M, Meurs A, et al. A decade of experience with deep brain stimulation for patients with refractory medial temporal lobe epilepsy. Int J Neural Syst. 2013;23:1250034.

Wilson WA, Swartzwelder HS, Anderson WW, Lewis DV. Seizure activity in vitro: a dual focus model. Epilepsy Res. 1988;2:289-93. 


\section{Legends of Figure and Tables}

Figure 1: Example of a BTLE patient with bilateral synchronous TL seizures (patient \#5); A: Sketch of the SEEG on a 3D surface brain representation. Each electrode contains 10-15 contacts. Electrode iTP' was placed in the left temporal pole. A' recorded the left superior temporal gyrus (lateral contacts) and the amygdala A (internal contacts). TB' was placed in the left temporo-basal area (external contacts) and in the entorhinal cortex [EC] (internal contacts). Electrode B' recorded the left middle temporal gyrus (external contacts) and the left anterior hippocampus (aHip), and B was its symmetrical. C' was placed in the posterior part of the left hippocampus (pHip). H' recorded the superior temporal gyrus [STG] (external contacts) and the insular cortex (temporal part, internal contacts). GL' recorded the posterior part of the lateral occipital sulcus on its external contacts and the lingual gyrus on its internal contacts. L' explored the visible lesion (the heterotopia) in its internal contacts. B: first seizure: SEEG recordings from the different regions of interest, showing a low-voltage rapid discharge in the left EC with a rapid involvement of left aHip, left pHip, left iTP as well as right aHip and a secondary involvement of left STG and A. C: another example of seizure displaying the same pattern D. Map of the Energy ratio calculated from the previous SEEG signals. The vertical red bars indicate the detection times for each signal SEEG signals $\mathbf{E}$. Graph of the EI values for each of the selected regions calculated from the previous seizure example.

Figure 2: Example of a BTLE patient with right and left independent TL seizures (patient \#14); A. Sketch of the SEEG. Each electrode contains 10-15 contacts. A recorded the right superior temporal gyrus (lateral contacts) and the amygdala (internal contacts) and A' was its symmetrical. TB was placed in the right inferior temporal gyrus (external contacts) and in the entorhinal cortex [EC] (internal contacts), and TB' on the contralateral homologous region. 
Electrode B recorded the right middle temporal gyrus (external contacts) and the left anterior hippocampus (aHip). $\mathrm{C}$ was placed in the posterior part of the right hippocampus (pHip) and C' explored the same region on the left side. GC recorded the supramarginal gyrus (external contacts) and posterior cingulate cortex (internal contacts). OR recorded the right FEF (external contacts) and the orbitofrontal region / gyrus rectus on its internal contacts. B: first seizure: SEEG recordings from the different regions of interest, showing a right mesiotemporal seizure. $\mathbf{C}$ : another seizure recorded in the same patient, a pure left mesiotemporal seizure D. Graph of the EI values obtained from the first seizure (B). E. Graph of the EI values obtained from 89the second seizure (C).

Figure 3: EI values, ranging from 0 (no epileptogenicity) to 1 (maximal epileptogenicity) in the different analyzed structures, in both groups. Higher EI values (=higher epileptogenicity) were found in the BTLE group in the posterior part of the parahippocampal gyrus $(\mathrm{p}=0.05)$ and in the UTLE group in the anterior hippocampus $(\mathrm{p}=0.005)$. 
Table 1: Demographic, clinical and neuroimaging findings in both groups of patients. Abbreviations: BTLE: bilateral temporal epilepsy, UTLE unilateral temporal epilepsy, R; right, L: left, FCD: focal cortical dysplasia, HS: hippocampal sclerosis, DNET: dysembryoplasic neuroepthelial tumour, VNS: vagal nerve stimulation, ATL: anterior temporal lobectomy, GK: gamma knife.

Table 2: SEEG and anatomical data including the different explored regions, the number of recorded seizures, the EZ and the number of epileptogenic structures (regions disclosing EI $>0.4$ ) for each patient in both groups. Abbreviations: L: left, R: right; iTP: internal temporal pole, eTP: external temporal pole, A: amygdala, EC: entorhinal cortex, aHip: anterior hippocampus, pHip: posterior hippocampus, pPHG: posterior part of the parahippocampal gyrus, STG: superior temporal gyrus, MTG: middle temporal gyrus, ITG: inferior temporal gyrus;O-T: occipito-temporal cortex. 
Table 1 :

\begin{tabular}{|c|c|c|c|c|c|c|c|}
\hline $\begin{array}{l}\text { B-MTLE } \\
\text { patients }\end{array}$ & $\begin{array}{l}\text { Gro } \\
\text { up }\end{array}$ & $\begin{array}{l}\text { Age at } \\
\text { epilepsy } \\
\text { onset }\end{array}$ & $\begin{array}{l}\text { Epilepsy } \\
\text { duration }\end{array}$ & MRI & FDG PET & $\begin{array}{l}\text { Therapeutic } \\
\text { actions }\end{array}$ & $\begin{array}{l}\text { Surg } \\
\text { ery }\end{array}$ \\
\hline 1 & $\begin{array}{c}\text { BTL } \\
\text { E }\end{array}$ & 15 & 44 & normal & * & medical treatment & * \\
\hline 2 & $\begin{array}{c}\text { BTL } \\
\text { E }\end{array}$ & 8 & 33 & R temporal FCD & R temporal hypometabolism & VNS $(12 / 2012)$ & * \\
\hline 3 & $\begin{array}{c}\text { BTL } \\
\text { E }\end{array}$ & 9 & 24 & $\mathrm{R} H \mathrm{HS}$ & L temporal hypometabolism & medical treatment & * \\
\hline 4 & BTL & 18 & 19 & normal & Lemporar mypomiclastiom & medical treatment & * \\
\hline 5 & $\begin{array}{c}\text { BTL } \\
\text { E }\end{array}$ & 16 & 23 & $\begin{array}{c}\text { L temporal periventricular } \\
\text { heterotopia }\end{array}$ & $\begin{array}{l}\mathrm{L} \text { post temporal } \\
\text { hypermetabolism } \\
\text { (heterotopia) }\end{array}$ & VNS (03/2012) & * \\
\hline 6 & BTL & 15 & 22 & hypothalamic hamartoma & $\begin{array}{l}\mathrm{L} \text { ant/int temporal } \\
\text { hypometabolism }\end{array}$ & VNS $(01 / 2012)$ & * \\
\hline 7 & BTL & 35 & 12 & R subhippocampal FCD & $\begin{array}{l}\text { bilateral prefrontal } \\
\text { hypometabolism }\end{array}$ & medical treatment & * \\
\hline 8 & BTL & 2 & 36 & 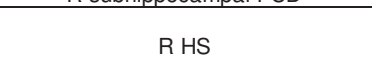 & L temporal hypometabolism & VNS $(05 / 2012)$ & * \\
\hline 9 & $\begin{array}{c}\mathrm{BTL} \\
\mathrm{E}\end{array}$ & 25 & 22 & bilateral HS $(L>R)$ & L temporal hypometabolism & medical treatment & * \\
\hline 10 & BTL & 7 & 36 & normal & L temporal hypometabolism & medical treatment & * \\
\hline 11 & $\begin{array}{c}\text { BTL } \\
\text { E }\end{array}$ & 11 & 6 & L HS & L temporal hypometabolism & left ATL (2012) & III \\
\hline 12 & $\begin{array}{c}\text { BTL } \\
\text { E }\end{array}$ & 13 & 19 & normal & normal & medical treatment & * \\
\hline 13 & BTL & 24 & 7 & L hippocampal atrophy & $\begin{array}{c}\text { bilateral hypometabolism } \\
(\mathrm{L}>\mathrm{R})\end{array}$ & medical treatment & * \\
\hline 14 & $\begin{array}{c}\text { BTL } \\
\text { E }\end{array}$ & 28 & 17 & normal & R temporal hypometabolism & VNS (03/2014) & * \\
\hline 15 & $\begin{array}{c}\text { BTL } \\
\mathrm{E}\end{array}$ & 12 & 28 & R hippocampal and amygdalar FCD & $\begin{array}{l}\text { bilateral hypometabolism } \\
(\mathrm{R}>\mathrm{L})\end{array}$ & VNS (12/2013) & * \\
\hline 16 & $\begin{array}{l}\text { UT } \\
\text { LE }\end{array}$ & 6 & 9 & L TL ganglioglioma & * & left ATL (2002) & III \\
\hline 17 & $\begin{array}{l}\text { UT } \\
\text { LE }\end{array}$ & 8 & 30 & normal & * & left ATL (2003) & III \\
\hline 18 & $\begin{array}{l}\text { UT } \\
\text { LE }\end{array}$ & 17 & 14 & L HS & * & $\begin{array}{l}\text { left AH (2002); left } \\
\text { ATL (2004) }\end{array}$ & II \\
\hline 19 & $\begin{array}{l}\text { UT } \\
\text { LE }\end{array}$ & 1 & 54 & L HS & * & $\begin{array}{l}\text { left GK (1993); left } \\
\text { ATL (2003) }\end{array}$ & I \\
\hline 20 & $\begin{array}{l}\text { UT } \\
\text { LE }\end{array}$ & 11 & 2 & R DNET & $\mathrm{R}$ temporal hypometabolism & ATL (2009) & I \\
\hline 21 & $\begin{array}{l}\text { UT } \\
\text { LE }\end{array}$ & 10 & 20 & R HS & * & right ATL (2000) & I \\
\hline 22 & $\begin{array}{l}\text { UT } \\
\text { LE }\end{array}$ & 25 & 13 & L HS & * & left ATL (2001) & I \\
\hline 23 & $\begin{array}{l}\text { UT } \\
\text { LE }\end{array}$ & 42 & 10 & normal & $\mathrm{L}$ temporal hypometabolism & left ATL (2013) & II \\
\hline 24 & $\begin{array}{l}\text { UT } \\
\text { LE }\end{array}$ & 6 & 38 & bilateral HS & L temporal hypometabolism & $\begin{array}{c}\text { left temporal } \\
\text { cortectomy (2013) }\end{array}$ & I \\
\hline 25 & $\begin{array}{l}\text { UT } \\
\text { LE }\end{array}$ & 8 & 19 & L HS & L temporal hypometabolism & left ATL (2009) & I \\
\hline 26 & $\begin{array}{l}\text { UT } \\
\text { LE }\end{array}$ & 37 & 4 & bilateral oligodendroglioma $(\mathrm{R}>\mathrm{L})$ & R temporal hypometabolism & right ATL (2010) & ॥ \\
\hline 27 & $\begin{array}{l}\text { UT } \\
\text { LE }\end{array}$ & 15 & 18 & 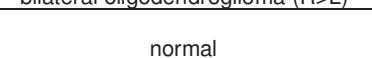 & $\begin{array}{c}\text { bilateral hypometabolism } \\
(\mathrm{L}>\mathrm{R})\end{array}$ & surgery refused & * \\
\hline 28 & $\begin{array}{l}\text { UT } \\
\text { LE }\end{array}$ & 17 & 10 & R hippocampal atrophy & R temporal hypometabolism & right GK (2011) & I \\
\hline 29 & $\begin{array}{l}\text { UT } \\
\text { LE }\end{array}$ & 6 & 36 & $\mathrm{RHS}$ & $\begin{array}{l}\mathrm{R} \text { temporo-perisylvian } \\
\text { hypometabolism }\end{array}$ & right ATL (2007) & I \\
\hline 30 & $\begin{array}{l}\text { UT } \\
\text { LE }\end{array}$ & 25 & 36 & $\begin{array}{l}\mathrm{R} \text { temporal lateral and polar }(+ \\
\text { frontal) post-traumatic lesion }\end{array}$ & R temporal hypometabolism & Right ATL (2013) & I \\
\hline
\end{tabular}


Table 2

\begin{tabular}{|c|c|c|c|}
\hline $\begin{array}{l}\text { B-MTLE } \\
\text { patients }\end{array}$ & Explored brain regions & Number of seizures /side & $\begin{array}{c}\text { Number of regions } \\
\text { disclosing EI }>0.4\end{array}$ \\
\hline 1 & $\begin{array}{c}\text { L: iTP, eTP, A, EC, aHip, pHip, pPHG, STG, MTG, ITG; } \\
\text { R: pHip, MTG }\end{array}$ & $2 \mathrm{~L}->\mathrm{R}$ & 3 \\
\hline 2 & R: aHip, EC, pPHG, STG, MTG, ITG; L: EC, ITG & $2 \mathrm{R} ; 1$ bilateral synchronous & 2 \\
\hline 3 & $\begin{array}{c}\text { R: EC, aHip, pHip, EC, STG, MTG, ITG, SMG; L: iTP, } \\
\text { eTP, EC, aHip, MTG, ITG }\end{array}$ & $\begin{array}{l}2 \mathrm{~L} ; 1 \text { bilateral synchronous; } 1 \\
\text { R->L ; } 4 \text { L-> R }\end{array}$ & 1 \\
\hline 4 & $\begin{array}{c}\text { R: A, aHip, pHip, EC, iTP, eTP, STG, MTG, ITG; L: aHip, } \\
\text { MTG }\end{array}$ & $\begin{array}{l}1 \mathrm{R} ; 1 \text { bilateral synchronous; } 1 \\
\text { R->L; } 2 \text { L->R }\end{array}$ & 2 \\
\hline 5 & $\begin{array}{l}\text { L: iTP, eTP, A, EC, aHip, pHip, pPHG, heterotopia, STG, } \\
\text { MTG, ITG; R: aHip, MTG }\end{array}$ & 2 bilateral synchronous & 2 \\
\hline 6 & $\begin{array}{c}\text { L:iTP, eTP, aHip, pHip, EC, STG, MTG, ITG; R: aHip, } \\
\text { iTP,eTP, MTG; hamartoma }\end{array}$ & $2 \mathrm{R} ; 1 \mathrm{~L} ; 1$ bilateral synchronous & \\
\hline 7 & $\begin{array}{c}\text { R: aHip, EC, pPHG, O-T region, G, MTG, ITG; L: EC, O-T } \\
\text { region, MTG }\end{array}$ & $2 \mathrm{~L} ; 3$ bilateral synchronous & 1 \\
\hline 8 & $\begin{array}{c}\text { R: iTP, eTP, A, aHip, pHip, EC, STG, MTG, iTG; L: aHip, } \\
\text { iTP, eTP, MTG }\end{array}$ & $\begin{array}{c}1 \mathrm{~L} ; 1 \text { bilateral synchronous ; } 1 \\
\mathrm{R}->\mathrm{L} ; 2 \mathrm{~L}->\mathrm{R}\end{array}$ & 2 \\
\hline 9 & $\begin{array}{l}\text { L: A, aHip, EC, pPHG, O-T region, STG, MTG, ITG; R: A, } \\
\text { aHip, O-T region, MTG }\end{array}$ & $1 \mathrm{~L} ; 2 \mathrm{R}->\mathrm{L}$ & 2 \\
\hline 10 & $\begin{array}{c}\text { L: iTP, eTP,A, aHip, pHip, EC, pPHG, MTG, iTG; R: aHip, } \\
\text { MTG }\end{array}$ & 3 bilateral synchronous; $1 \mathrm{R}->\mathrm{L}$ & 3 \\
\hline 11 & $\begin{array}{c}\text { R: iTP, eTP, A, aHip,EC, pPHG, O-T region STG, MTG, } \\
\text { ITG; L: aHip, MTG }\end{array}$ & $\begin{array}{c}3 \mathrm{R} ; 2 \mathrm{~L} ; 1 \text { bilateral synchronous; } \\
1 \mathrm{R}->\mathrm{L}\end{array}$ & 3 \\
\hline 12 & $\begin{array}{c}\text { L: iTP, eTP, aHip, pHip, EC, pPHG, MTG, ITG; R: } \\
\text { aHip,pPHG, MTG, ITG }\end{array}$ & $\begin{array}{c}1 \mathrm{~L} ; 5 \text { bilateral synchronous; } 1 \\
\mathrm{R}->\mathrm{L}\end{array}$ & 2 \\
\hline 13 & $\begin{array}{l}\text { L: A, EC, aHip, pHip, MTG, ITG ; R: A, EC, aHip, pHip, } \\
\text { MTG, ITG }\end{array}$ & $1 \mathrm{~L} ; 1 \mathrm{R}->\mathrm{L} ; 1 \mathrm{~L}->\mathrm{R}$ & 2 \\
\hline 14 & $\begin{array}{l}\text { R: A, aHip, pHip, EC, MTG, ITG ; L: A, pHip, EC, MTG, } \\
\text { ITG }\end{array}$ & $4 \mathrm{R} ; 1 \mathrm{~L} ; 1 \mathrm{~L}->\mathrm{R}$ & 2 \\
\hline 15 & L: A, aHip, pHip, EC; R: A, pHip, EC, MTG, ITG & $1 \mathrm{~L} ; 1 \mathrm{R}->\mathrm{L} ; 2 \mathrm{~L}->\mathrm{R}$ & 3 \\
\hline
\end{tabular}

\begin{tabular}{|c|c|c|c|}
\hline $\begin{array}{l}\text { U-MTLE } \\
\text { patients }\end{array}$ & Explored brain regions & Number of recorded seizures & $\begin{array}{c}\text { Number of regions } \\
\text { disclosing EI }>0.4\end{array}$ \\
\hline 16 & L: A, pHip, EC, MTG, ITG, O-T region; R: aHip, MTG & 4 & 2 \\
\hline 17 & $\begin{array}{c}\text { L: A, aHip, pHip, EC, MTG, ITG, iTP, eTP; R; aHip, EC, } \\
\text { MTG, ITG }\end{array}$ & 7 & 3 \\
\hline 18 & R: A, aHip, pHip, iTP, eTP, EC, MTG, ITG; L: aHip, MTG & 2 & 1 \\
\hline 19 & L: A, pHip, EC, pPHG, MTG, ITG; R: A, MTG & 5 & 4 \\
\hline 20 & R: iTP, eTP, EC, A, pHip, MTG, ITG; 1: EC, A, MTG, ITG & 4 & 2 \\
\hline 21 & iTP, eTP, EC, A, aHip, pHip, MTG, ITG; R: aHip, MTG & 5 & 4 \\
\hline 22 & $\begin{array}{l}\text { L: A, aHip, pHIp, iTP, eTP, EC, MTG, ITG; R: aHip, pHip, } \\
\text { MTG }\end{array}$ & 4 & 4 \\
\hline 23 & $\begin{array}{c}\text { L: A, aHip, pHip, EC, pPHG, iTP, eTP, STG, MTG, ITG; } \\
\text { R: EC }\end{array}$ & 3 & 3 \\
\hline 24 & L: aHip, iTP, eTP, EC, A, MTG, ITG; R: aHip, EC, MTG & 2 & 2 \\
\hline 25 & L: A, aHip, pHip, EC, pPHG, MTG, ITG & 2 & 1 \\
\hline 26 & $\triangle \mathrm{R}: \mathrm{A}, \mathrm{EC}, \mathrm{pPHG}, \mathrm{STG}, \mathrm{MTG}, \mathrm{ITG}$; L: EC, MTG & 2 & 1 \\
\hline 27 & $\begin{array}{c}\text { R: iTP, eTP, aHip, EC, pPHG, O-T region, MTG, ITG; L: } \\
\text { EC, O-T region, MTG }\end{array}$ & 2 & 1 \\
\hline 28 & R: iTP, eTP, A, EC, aHip, pHip, STG, MTG, ITG & 2 & 2 \\
\hline 29 & R: iTP, eTP, A, pHip, EC, STG, MTG, ITG & 2 & 2 \\
\hline 30 & $\begin{array}{c}\text { R: iTP, eTP, aHip, pHip, EC, STG, MTG, ITG; L: iTP, } \\
\text { eTP, EC, MTG }\end{array}$ & 2 & 1 \\
\hline
\end{tabular}


A

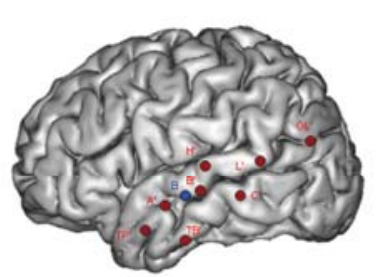

c

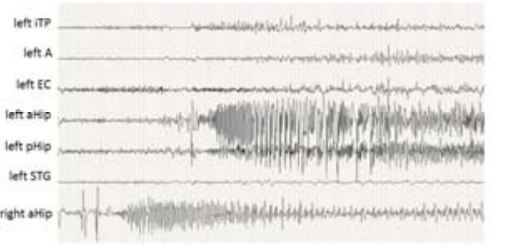

E
B
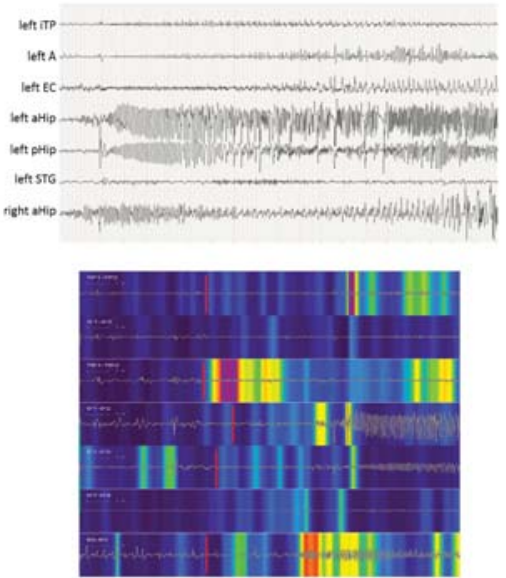

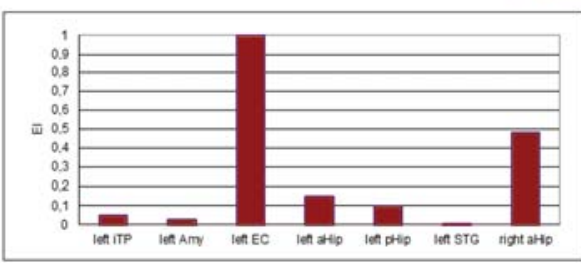


A
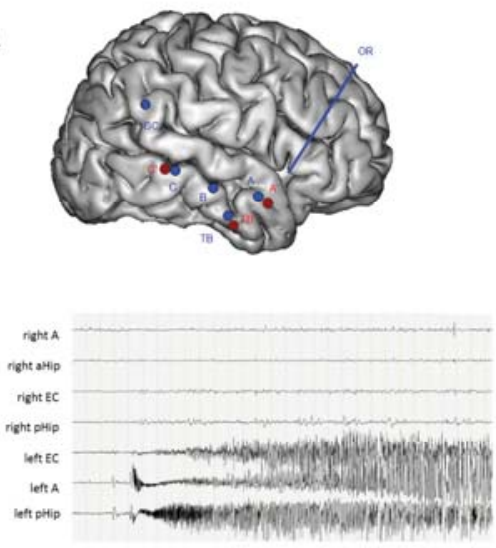

E

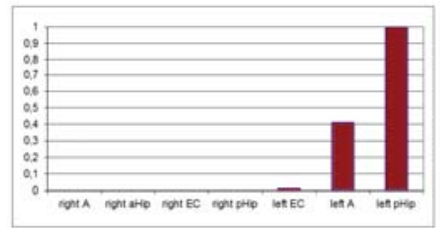

C

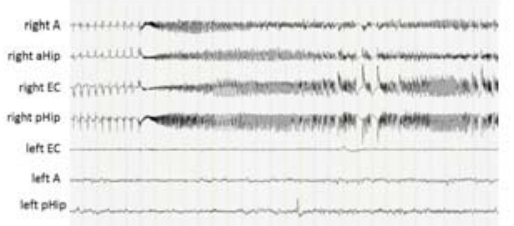

D

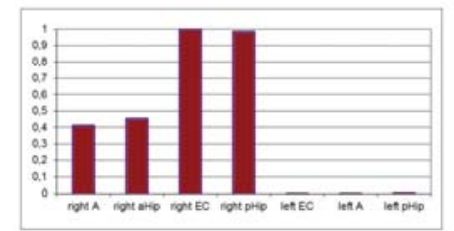




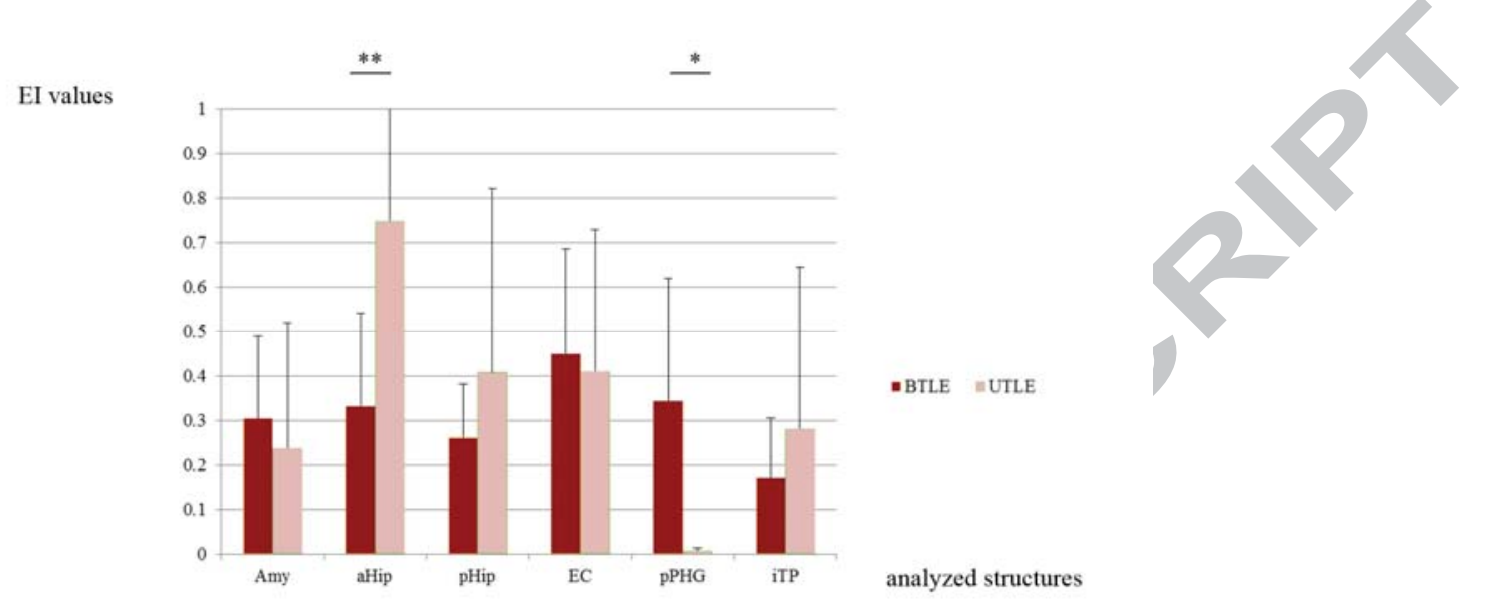

